\title{
Synchrotron Radiation in Biology and Medicine
}

\author{
J.B. PEeKA* \\ Institute of Physics, Polish Academy of Sciences \\ al. Lotników 32/46, 02-668 Warsaw, Poland
}

\begin{abstract}
This work is focused on a present status of synchrotron radiation X-ray applications in medicine and biology to imaging, diagnostics, and radiotherapy. Properties of X-ray beams generated by synchrotron sources are compared with radiation produced by classical laboratory X-ray tubes. A list of operating and planned synchrotron facilities applicable to biomedical purposes is given, together with their basic characteristics. A concise overview of typical X-ray synchrotron techniques in biology and medicine is carried out with discussion of their specific properties and examples of typical results.
\end{abstract}

PACS numbers: 87.57.-s, 87.59.-e, 07.85.Fv, 07.90.+c

\section{Introduction}

Importance of synchrotron radiation (SR) in science and technology cannot be overestimated. At present, all over the world, about 80 large and medium size storage rings are producing altogether hundreds of intense collimated light beams. With unique combination of properties, the beams facilitate a detailed insight in structure and processes of matter. Application of SR exerts a significant impact on development in many areas of condensed matter physics, chemistry, material science and engineering, as well as of other sciences. Since more than thirty years, synchrotron radiation has also been extensively used in life sciences and in medicine, opening up new opportunities in studying life forms on different levels, from organisms as a whole, including human, through organs and tissues, to cells and subcellular structures $[1,2]$. Intense synchrotron X-ray beams turned out to be invaluable in soft tissue imaging, diagnostics and therapy. A number of life science-related synchrotron projects grow rapidly, and will soon dominate over other applications of synchrotron radiation.

In many instances, employment of synchrotron radiation opens up new frontiers in exploring biological phenomena, with their dynamics studied in real time,

*corresponding author; e-mail: pelkay@ifpan.edu.pl 
in vivo, not only by imaging or X-ray microscopy, but also by numerous spectroscopic techniques. Under development are new, SR specific techniques for diagnosis and therapy, designed for clinical applications to treat human patients. The new techniques allow us to learn far more, as compared to methods with classic radiation sources, about cellular events such as gene expression and regulation, immune recognition, transmembrane transport, cell signaling, enzymatic reactions and protein synthesis. With this knowledge, it is easier to find the efficient means to tackle such diseases as atherosclerosis, diabetes, Parkinson, Alzheimer's, and many other. Synchrotron light makes it possible to spot tiny, early-stage tumors to apply precisely a cancer treatment and to monitor its results.

SR sources constitute also an excellent tool to determination of biologically active molecular structures [3]. More than $80 \%$ protein structures, out of more than 45000 collected in Protein Data Bank (PDB), have been solved with aid of X-ray synchrotron beams, contributing in better understanding of fundamental life processes and in exploring interaction mechanisms of drugs with organisms and with pathogens. It helps in advancing the design of drugs, enabling greatly reduced dosages and improved outcomes. Most of us benefit in everyday life from the progress induced by these investigations, taking new, more efficient and less toxic medicals, or undergoing to a new type of diagnostic check.

This article presents a concise overview of SR application in medicine and biology with main attention paid to the methods exploiting X-rays. Starting from comparison between classic laboratory and synchrotron sources of X-ray beams, basic types of SR methods and techniques are discussed and examples of their biomedical applications in diagnostics and radiotherapy are given.

\section{X-ray SR sources for biomedical applications}

$\mathrm{X}$-ray photon energies exploited in biomedical investigations range from about $8-10 \mathrm{keV}$ up to $150 \mathrm{keV}$. Photon beams of higher photon energy, in the range of a few hundreds $\mathrm{keV}$ and higher, in the gamma ray region, are used in radiotherapy. Typical photon energies applied in exemplary radiographic methods are collected in Table I. Human body is practically opaque for photons of energies below $10 \mathrm{keV}$. However, even softer radiation is applied in some surface sensitive spectroscopic techniques and in case of X-ray imaging of thin soft tissue films.

Specificity of biomedical applications of X-rays results primarily from a narrow dispersion in absorption coefficients of various tissue types, except bone tissue. This is evidenced by a common experience of a standard X-ray radiograph, e.g. of thorax or limb, with apparently reproduced bones, whereas other types of soft tissue are hardly distinguishable from each other. X-ray densities of exemplary tissue types, expressed by absorption length at a fixed photon energy of $40 \mathrm{keV}$ are compared in Table II [4]. These small differences in absorption length make absorption contrast often not sufficient at the task of distinguishing between different kinds of soft tissue. Absorbed X-ray beam energy, due to ionizing character of 
TABLE I

Typical X-ray photon energies applied in various methods of clinical radiology and radiotherapy.

\begin{tabular}{l|c}
\hline \hline Application & $\begin{array}{c}\text { Photon energies } \\
{[\mathrm{keV}]}\end{array}$ \\
\hline mammography & $17-25$ \\
stomatology & $60-70$ \\
thorax radiography & $50-90$ \\
radiotherapy & $30-150^{+}$ \\
coronarography & 50 \\
& (with Gd contrast)
\end{tabular}

TABLE II

Radiological properties of selected tissue types.

\begin{tabular}{c|c|c|c|c}
\hline \hline Material & $Z / A$ & $\begin{array}{c}\text { Density, } \rho \\
{\left[\mathrm{g} / \mathrm{cm}^{3}\right]}\end{array}$ & $\begin{array}{c}\text { Mass absorption } \\
\text { coefficient, } \\
\mu / \rho \text { at } 40 \mathrm{keV}\left[\mathrm{cm}^{2} / \mathrm{g}\right]\end{array}$ & $\begin{array}{c}\text { Attenuation length } \\
\text { at } 40 \mathrm{keV} \\
{[\mathrm{cm}]}\end{array}$ \\
\hline adipose tissue & 0.5558 & 0.950 & 0.2396 & 4.3933 \\
water & 0.5551 & 1.000 & 0.2683 & 3.7272 \\
breast tissue & 0.5520 & 1.020 & 0.2530 & 3.8751 \\
brain tissue & 0.5524 & 1.040 & 0.2702 & 3.5586 \\
lung tissue & 0.5505 & 1.050 & 0.2699 & 3.5286 \\
skeletal muscle & 0.5500 & 1.050 & 0.2685 & 3.5470 \\
blood & 0.5500 & 1.060 & 0.2715 & 3.4748 \\
cortical bone & 0.5148 & 1.920 & 0.6655 & 0.7826
\end{tabular}

X-rays, generates a damage of biological objects. As a consequence, life functions can be disturbed by radiation defects introduced in molecular structure of cells, including DNA strands. In case of higher absorbed irradiation doses, the damage can be lethal to cells, or even to organism as a whole. The above properties, thoroughly discussed in literature, bear distinct obstacles in biomedical applications of X-rays, in particular in obtaining X-ray radiographs of diagnostically valuable contrast with reasonably low irradiation doses.

In clinical radiology, the X-ray beams are produced mostly by conventional $\mathrm{X}$-ray tube generators and medical accelerators exploiting bremsstrahlung process of electron beam losing its energy in a target material. Photon flux generated in a standard medical X-ray tube can reach $10^{12}$ photons $/ \mathrm{s} \times 4 \pi$ (in all directions, without collimation). Spectral brightness [5] of $\mathrm{Cu} K_{\alpha}$ radiation emitted from the most intense rotating anode tubes, expressed in units used for characterization of collimated synchrotron radiation does not exceed $10^{11}$ photons $/ \mathrm{s} \mathrm{mrad}^{2} \mathrm{~mm}^{2}$ $0.1 \%$ BW [6]. A beam from a conventional tungsten X-ray tube, operating at a 
voltage of $110 \mathrm{kV}$ with $2.5 \mathrm{~mm}$ thick Al filter, reaches spectral brightness of $10^{10}$ photons $/ \mathrm{s} \mathrm{mrad}^{2} \mathrm{~mm}^{2} 0.1 \% \mathrm{BW}$ of tungsten $K_{\alpha}$ radiation [7].

Currently, synchrotron radiation is produced typically in dedicated circular accelerators, called storage rings or synchrotrons ${ }^{\dagger}$. The storage ring includes both straight and curved sections of a vacuum tube. Contrary to bremsstrahlung process exploited in X-ray emission at classical sources, synchrotron radiation relies on trajectory changes of a beam of ultrarelativistic electrons (or positrons) in a strong magnetic field. The electron beam, circulating in the ring, passes through bending magnets $(\mathrm{BM})$ placed in the curved sections, where it is deflected by several degrees. As a result, a strong radiation is emitted tangentially to the beam trajectory. Thus, bending magnets, the basic SR sources at every synchrotron, produce a well collimated beam of radiation of continuous spectral distribution ranging from infrared (IR) up to a maximal photon energy. This energy, with values typically in the hard X-ray region, depends on intensity of the deflecting magnetic field and on the kinetic energy of electron beam in the accelerator ring. More powerful radiation is created in other types of SR sources that can be inserted in straight sections of storage ring: wigglers (W) and undulators (U). In these sources the electrons are deflected by a number of magnetic poles distributed periodically along their trajectory. This results in periodic oscillations of the beam charge. Radiation produced at the oscillations interfere, giving thus a more intense and better collimated beam at output. Similarly to BM, the W deliver collimated beams of broad, white spectrum, ranging from far IR up to hard X-rays. Spectral distribution of radiation from $U$ has a few intense peaks at discrete photon energies and, much weaker, a continuous radiation.

All the above mentioned SR source types, the bending magnets, the wigglers and the undulators deliver intense, well collimated beams, of high polarity and a partial spatial coherence. Radiation of analogous characteristics is not achievable with classical X-ray sources. In addition, due to bunch structure of e-beam travelling in accelerator tube, SR is delivered in trains of pulses, of the length typically in the range of 20 to $100 \mathrm{ps}$, with values closer to $20-30 \mathrm{ps}$ in newly designed machines. Spectral brightness of monochromatized X-ray beams produced in 2GLS and 3GLS (GLS stands for generation light source, 2 and 3GLS refers to classical circular synchrotron accelerators, see, eg. [8] for explanation), comprises in the range of $10^{11}-10^{20}$ photons/s $\mathrm{mrad}^{2} \mathrm{~mm}^{2} 0.1 \% \mathrm{BW}$, depending on type and operational parameters of a particular synchrotron source [9].

Currently, underway is construction of 4 th generation SR sources (4GLS), the free electron lasers (FELs). Various types of FELs can deliver radiation in the

\footnotetext{
${ }^{\dagger}$ Term synchrotron is used in this article exclusively to denote electron (positron) circular accelerators dedicated to synchrotron radiation. Apart this meaning, it refers also to facilities that accelerate other types of charged particles, like protons, or to $\mathrm{e}^{+} \mathrm{e}^{-}$ circular colliders, and typically are not used as SR sources.
} 
spectral regions ranging from microwaves to ultraviolet and to X-ray regions. The FELs emitting in the XUV and X-ray range utilize a relativistic electron beam as a lasing medium providing monochromatic radiation structured in ultrafast pulses, of duration down to the fs range, with a unique combination of tunability, coherence, polarization, and high power that can reach in a single pulse as much as a few GW. Spectral brightness of the new X-FEL sources, to be operational in the next few years, will be up to 9 orders of magnitude higher, as compared to the most intense now 3GLS sources, reaching values of $10^{29}$ photons $/ \mathrm{s} \mathrm{mrad}^{2}$ $\mathrm{mm}^{2} 0.1 \%$ BW delivered in ultrafast pulses of only $10-50 \mathrm{fs}[10,11]$. Though direct application of the X-FEL sources to the biomedical imaging or radiotherapy is still a matter of discussion, they are expected to have a decisive impact on development of biological science. In particular, X-FELs will certainly revolutionize structural biology with a unique opportunity of diffraction imaging of non-periodic structures, at a spatial resolution on nanometric and micrometric scales, especially important to biology [12-14]. Power and flexibility of the short-wavelength FELs is just being extensively studied with the FLASH facility in DESY (Hamburg), operating in the XUV photon energy range. The FLASH is a prototype to the European $\mathrm{X}$-FEL laser being constructed in the same center in Hamburg. The results of the tests show that FELs radiating in the range of XUV to X-rays will offer unparalleled opportunities for the study of processes occurring on ultrashort time and length scales, in medicine, biology, biochemistry, and in related fields of science and technology $[15,16]$.

Typical photon energies in synchrotron beams dedicated to biomedical applications cover the, mentioned earlier, range from 8-10 keV up to $120-150 \mathrm{keV}$, that is in use in conventional X-ray radiology. The range is at synchrotrons extended down to UV, VIS and even to infrared regions in some imaging and spectroscopic techniques aimed on examination of tissues, cells and sub-cellular structures. Intense sources operating both in polychromatic and in a monochromatic mode at easily tuned photon energy are strongly favorable in the most of diagnostic and radiotherapy applications with live objects subjected directly to radiation. From this point of view optimal to the biomedical applications are beams produced in BM and $\mathrm{W}$ sources at synchrotrons operating with electron beam energy not less than $2.4 \mathrm{GeV}$ and of possibly high e-beam current in the accelerator ring. To achieve higher radiation intensities, whenever possible, superconducting wigglers working with high magnetic fields are installed. Until recently, undulators have been installed sporadically to this purpose, however new advancements in construction of tunable, intense undulator sources can change the situation.

Beams of possibly high brilliance permit to minimize exposure times. This is crucial in investigation of dynamics of life processes and helps avoiding image blur due to physiological involuntary movements, like that of lungs, liver or heart, e.g., in bronchography or coronarography. Entrance dose rates attainable with intense SR sources can exceed even $20000 \mathrm{~Gy} / \mathrm{s}$. For comparison, a high-power 
laboratory analytical X-ray tube delivers, close to the tube output window, a dose rate not higher than $100 \mathrm{~Gy} / \mathrm{s}$. Intense white beams facilitate also obtaining monochromatic beams. Monochromatization can suppress output intensity by 2-6 orders of magnitude, depending on details of X-ray optics. Therefore, the intensity of a relatively weak monochromatic SR source, can be, in some cases, not much higher than the intensity of a white beam from conventional medical X-ray tube.

Maximization of radiated intensity from SR sources is useful in some radiological methods, where large beam cross-sections with a reasonable dose density of radiation are advantageous. An example can be the BL20B2 beamline at SPring- 8 with largest cross-section of $300 \times 20 \mathrm{~mm}^{2}$ at the object position. This spot size has been reached by elongation of the beamline to $\approx 280 \mathrm{~m}$ (from source to experimental hall) without increasing the BL20B2 beam divergence of $1.5 \times 0.06 \mathrm{mrad}^{2}$ $(\mathrm{H} \times \mathrm{V})$, the values typical of SR beams level of collimation.

In Table III, a comparison of synchrotron facilities for biomedical applications is shown. Listed are only large and medium size machines, working with electron beam energies not less than $2.4 \mathrm{GeV}$. The table is divided into three subsections: the first deals with facilities fully operating, the other collects new facilities with only part of infrastructure operational. The last includes the facilities being designed and in construction phase; in this number listed are the newest projects of national synchrotron facilities planned in Central Europe, in Poland (Kraków) and in Czech Republic (Brno). Columns 2-6 are related to general characteristics of the synchrotrons. Data specific to dedicated biomedical beamlines of the machines are shown in columns 7-13. In Table IV basic methods available at these beamlines are listed. Acronym expansions applied in Table IV commonly used in SR biomedical radiology, are explained in Table V. Apart the dedicated beamlines, biomedical investigations are also carried out at many of general purpose beamlines of virtually all synchrotrons. It is a typical case with methods exploiting lower photon energies and less intense beamlines, like, e.g., imaging of tissue preparations by X-ray phase contrast.

Since a decade, most of new synchrotron facilities are of average size (of circumference $170-300 \mathrm{~m}$ ) operating with intermediate electron beam energies in the range of $2.4-3.5 \mathrm{GeV}$. Until recently, from among 15 machines built or designed since year 2000, only three: DIAMOND (Chilton), NSLS II (Brookhaven, in design phase), and PETRA III (Hamburg, under construction), are of significantly larger circumference, $561.5 \mathrm{~m}, 791.5 \mathrm{~m}$, and $2304 \mathrm{~m}$, respectively. This facilitates obtaining SR beams of low emittance, high critical energy and high spectral brightness, features that are advantageous in numerous applications. Petra III, with electron beam energy of $6 \mathrm{GeV}$, is in this group the only representative of large size synchrotron facilities. Application of superconducting wigglers (SCW), operating at high magnet fields of the order of $4-5 \mathrm{~T}$ as sources of intense white beams is other pronounced trend in the last decade. In spite of some difficulties in an optimized 
TABLE III a Parameters of synchrotron facilities fully operating at e-beam energies above $2.3 \mathrm{GeV}$ and characteristics of beamlines dedicated to biomedical applications. 1 - source name and location; 2 - start/upgrade year; 3 - energy [GeV]; 4 - circumference $[\mathrm{m}] ; 5$ - beam current $[\mathrm{mA}] ; 6$ - emittance $[\mathrm{nm} \mathrm{rad}] ; 7$ dedicated medical beamlines; 8 - source type ${ }^{b} ; 9$ - source field $B_{\max }[\mathrm{T}] ; 10$ - power emitted $[\mathrm{kW}] ; 11$ - critical energy $^{a}[\mathrm{keV}] ; 12-K_{\max } ; 13-$ present status $^{c}$

\begin{tabular}{|c|c|c|c|c|c|c|c|c|c|c|c|c|}
\hline \multicolumn{6}{|c|}{ Synchrotron characteristics } & \multicolumn{7}{|c|}{ Medical beam characteristics } \\
\hline 1 & 2 & 3 & 4 & 5 & 6 & 7 & 8 & 9 & 10 & 11 & 12 & 13 \\
\hline $\begin{array}{l}\text { DORIS III } \\
\text { Hamburg, D }\end{array}$ & $\begin{array}{l}1974 \\
1991\end{array}$ & 4.5 & 289.2 & 140 & 450 & $\begin{array}{c}1 \\
\mathrm{w} 2\end{array}$ & $\mathrm{~W}$ & 1.98 & 25 & 27 & 20.3 & $\begin{array}{c}\text { closed } \\
2001\end{array}$ \\
\hline $\begin{array}{l}\text { KEK PF } \\
\text { Tsukuba, J }\end{array}$ & $\begin{array}{l}1982 \\
1997 \\
\end{array}$ & 2.5 & 187 & 450 & 36 & $\begin{array}{c}1, \\
\text { bl-14c1 }\end{array}$ & SCW & 5 & & 20.8 & 2.0 & $\mathrm{O}$ \\
\hline $\begin{array}{l}\text { KEK PF-AR } \\
\text { Tsukuba, J }\end{array}$ & $\begin{array}{l}1986 \\
2002\end{array}$ & 6.5 & 377 & 55 & 293 & $\begin{array}{c}1, \\
\text { bl-nm5a }\end{array}$ & $\mathrm{BM}$ & 0.94 & 0.34 & 26 & $\mathrm{O}$ & \\
\hline $\begin{array}{l}\text { NSLS, } \\
\text { Brookhaven, } \\
\text { US }\end{array}$ & $\begin{array}{l}1984 \\
2006\end{array}$ & 2.8 & 170 & 300 & & $\begin{array}{c}1, \\
\times 15 \mathrm{a} \\
\text { (shared) }\end{array}$ & $\mathrm{BM}$ & 1.36 & & 7.1 & & $\mathrm{O}$ \\
\hline $\begin{array}{l}\text { Pohang LS } \\
\text { Pohang, KR }\end{array}$ & 1994 & 2.5 & 280.5 & 182 & 13 & & & & & & & \\
\hline $\begin{array}{l}\text { Siberia-2 } \\
\text { Moscow, RUS }\end{array}$ & 1996 & 2.5 & 124.13 & 300 & 98 & $\begin{array}{c}1, \\
\text { mediana }\end{array}$ & $\mathrm{BM}$ & 1.7 & & 7.1 & & \\
\hline $\begin{array}{l}\text { ESRF } \\
\text { Grenoble, F }\end{array}$ & 1994 & 6 & 844 & 160 & 4 & $\begin{array}{c}1, \\
\text { id-17 }\end{array}$ & $\mathrm{W}$ & 1.4 & 14.4 & 33.5 & 19.6 & $\mathrm{O}$ \\
\hline $\begin{array}{l}\text { ELETTRA } \\
\text { Trieste, I }\end{array}$ & 1994 & $\begin{array}{c}2 \\
2.4\end{array}$ & 260 & $\begin{array}{l}150 \\
100\end{array}$ & $\begin{array}{c}7 \\
9.7\end{array}$ & $\begin{array}{c}1, \\
\text { bl6.1r } \\
\text { syrmep }\end{array}$ & $\mathrm{BM}$ & 1.2 & & $\begin{array}{l}3.21 \\
5.59\end{array}$ & & $\mathrm{O}$ \\
\hline $\begin{array}{l}\text { APS } \\
\text { Argonne, US }\end{array}$ & 1996 & 7 & 1104 & 100 & 2.5 & & & & & & & \\
\hline $\begin{array}{l}\text { Spring-8 } \\
\text { Hyogo, J }\end{array}$ & 1997 & 8 & 1436 & & 3.5 & $\begin{array}{c}2, \\
\text { bl20b2 } \\
\text { bl20xu }\end{array}$ & $\begin{array}{c}\mathrm{BM} \\
\mathrm{U}\end{array}$ & 0.679 & 13.9 & 28.9 & 2.12 & $\mathrm{O}$ \\
\hline $\begin{array}{l}\text { Swiss LS } \\
\text { Villigen, CH }\end{array}$ & 2001 & 2.4 & 288 & 400 & 5 & - & & & & & & \\
\hline $\begin{array}{l}\text { ANKA } \\
\text { Karlsruhe, D }\end{array}$ & 2003 & 2.5 & 110.4 & 200 & 50 & - & & & & & & \\
\hline
\end{tabular}

accelerator lattice design, this type of source seems to be optimal to the dedicated biomedical line in a medium-sized synchrotron facility.

A fully equipped and failure-free operating synchrotron facility, that comes typically after few years since its start, offers radiation simultaneously even at 30-40 SR sources (e.g., at ESRF or DORIS III). Many of nowadays operating machines, including all 3GLS facilities [17] ensure continuous, stable operation through more than 330 days a year. This results in up to about 8 thousand experimental hours at a single beamline. Assuming 20 beamlines operating in parallel, we get 
TABLE IIIb

Parameters of synchrotron facilities operating partially, under construction and in design, with e-beam energies above $2.3 \mathrm{GeV}$ and characteristics of beamlines dedicated to biomedical applications. 1 - source name and location; 2 - start year, the 2nd date indicates planned year of full operation; 3 - energy $[\mathrm{GeV}]$; 4 - circumference $[\mathrm{m}] ; 5$ - beam current $[\mathrm{mA}] ; 6$ - emittance [nm rad]; 7 dedicated medical beamlines; 8 - source type $^{b} ; 9-$ source field $B_{\max }[\mathrm{T}] ; 10$ — power emitted $[\mathrm{kW}] ; 11-$ critical energy $^{a}[\mathrm{keV}] ; 12-K_{\max } ; 13$ - present status $^{c}$.

\begin{tabular}{|c|c|c|c|c|c|c|c|c|c|c|c|c|}
\hline \multicolumn{6}{|c|}{ Synchrotron characteristics } & \multicolumn{7}{|c|}{ Medical beam characteristics } \\
\hline 1 & 2 & 3 & 4 & 5 & 6 & 7 & 8 & 9 & 10 & 11 & 12 & 13 \\
\hline \multicolumn{13}{|c|}{ New machines, operating with a part of infrastructure } \\
\hline $\begin{array}{l}\text { SPEAR } 3 \\
\text { Berkeley, US }\end{array}$ & $\begin{array}{l}2004 \\
2007 \\
\end{array}$ & 3 & 234 & \begin{tabular}{|l|}
100 \\
500 \\
\end{tabular} & 18 & - & & & & & & \\
\hline $\begin{array}{l}\text { Canadian LS } \\
\text { Saskatoon, } \\
\text { CA [44] }\end{array}$ & $\begin{array}{l}2004 \\
2009\end{array}$ & 2.9 & 170 & 200 & 18.1 & $\begin{array}{c}2, \\
\text { bmit }\end{array}$ & $\begin{array}{c}\mathrm{BM} \\
\mathrm{SCW}\end{array}$ & $\begin{array}{c}1.35 \\
4.4\end{array}$ & 35 & $\begin{array}{l}7.5 \\
9.6\end{array}$ & & $\begin{array}{l}\mathrm{O} \\
\mathrm{C}\end{array}$ \\
\hline $\begin{array}{l}\text { DIAMOND } \\
\text { Chilton, UK }\end{array}$ & $\begin{array}{l}2007 \\
2009\end{array}$ & 3 & 561.6 & $\begin{array}{l}200 \\
500\end{array}$ & 2.7 & - & & & & & & \\
\hline $\begin{array}{l}\text { Australian LS } \\
\text { Melbourne, } \\
\text { AUS [45] }\end{array}$ & $\begin{array}{l}2007 \\
2009\end{array}$ & 3 & 216 & 200 & 7 & $\begin{array}{c}1, \\
\text { bl-10 } \\
{[46]}\end{array}$ & $\begin{array}{c}\mathrm{W} \\
\mathrm{SCW}\end{array}$ & $\begin{array}{c}1.4 \\
4.17\end{array}$ & $\begin{array}{l}5.2 \\
30\end{array}$ & $\begin{array}{l}8.3 \\
25\end{array}$ & $\begin{array}{l}11.1 \\
18.7\end{array}$ & $\begin{array}{l}\mathrm{O} \\
\mathrm{C}\end{array}$ \\
\hline $\begin{array}{l}\text { SOLEIL } \\
\text { Saint-Aubin, F }\end{array}$ & $\begin{array}{l}2007 \\
2009 \\
\end{array}$ & 2.75 & 354 & & 3.8 & $?$ & & & & & & \\
\hline $\begin{array}{l}\text { ALBA } \\
\text { Barcelona, E }\end{array}$ & $\begin{array}{l}2007 \\
2009\end{array}$ & 3 & 268.8 & 200 & 3.5 & $\begin{array}{l}\text { planned } \\
\text { in IInd } \\
\text { ph. [47] }\end{array}$ & SCW & 4.4 & & & & $\mathrm{P}$ \\
\hline \multicolumn{13}{|c|}{ Machines under construction and in design } \\
\hline $\begin{array}{l}\text { Petra III [48] } \\
\text { Hamburg, D }\end{array}$ & 2009 & 6 & 2304 & \begin{tabular}{|l|}
100 \\
200 \\
\end{tabular} & 1 & $?$ & & & & & & \\
\hline $\begin{array}{l}\text { SSRF } \\
\text { Shanghai, CN }\end{array}$ & 2009 & 3.5 & 432 & 300 & 3.9 & $\begin{array}{l}\text { incl. } \\
\text { in Ist } \\
\text { phase }\end{array}$ & $\mathrm{W}$ & 1.8 & & & & $\mathrm{C}$ \\
\hline $\begin{array}{l}\text { SESAME } \\
\text { Allaan, JOR }\end{array}$ & 2011 & 2.5 & 133.12 & 400 & 25 & 1 & & & & & & $\mathrm{C}$ \\
\hline $\begin{array}{l}\text { NSLS II [49] } \\
\text { Brookhaven }\end{array}$ & 2015 & 3 & 791.5 & 500 & 2.1 & $>1$ & & & & & & $\mathrm{P}$ \\
\hline $\begin{array}{l}\text { MAX IV } \\
\text { (X-ray) Lund, } \\
\text { S }[50,51]\end{array}$ & $>2015$ & 3 & 287.2 & 500 & 0.8 & $?$ & & & & & & $\mathrm{P}$ \\
\hline $\begin{array}{l}\text { PNLS } \\
\text { Cracow, PL } \\
\end{array}$ & $>2015$ & 3 & 268 & 500 & 3 & $1(2)$ & $\mathrm{SCW}$ & 4.4 & & & & $\mathrm{P}$ \\
\hline $\begin{array}{l}\text { CESLAB } \\
\text { Brno, CZ }\end{array}$ & $>2015$ & 3 & 268 & 200 & 3.5 & 1 & & & & & & $\mathrm{P}$ \\
\hline $\begin{array}{l}\text { CANDLE } \\
\text { Yerevan, AM }\end{array}$ & $?$ & 3 & 216 & 350 & 8.4 & 1 & $\mathrm{~W}$ & 1.98 & 29.9 & 11.88 & & $\mathrm{P}$ \\
\hline
\end{tabular}

150-160 thousand beam hours a year. This illustrates a high potential of research opportunities provided by the synchrotrons. 
TABLE IV

Main applications of synchrotron radiation sources.

\begin{tabular}{l|l}
\hline $\begin{array}{l}\text { Source name and loca- } \\
\text { tion }\end{array}$ & \multicolumn{1}{|c}{ Main techniques } \\
\hline DORIS III Hamburg, D & $\begin{array}{l}\text { dichromography, angiography, NIKOS, imaging tech- } \\
\text { niques }\end{array}$ \\
\hline KEK PF Tsukuba, J & $\begin{array}{l}\text { PCI, angiography, micro-angiography, monochromatic } \\
\text { CT, DEI, fluorescent X-ray imaging }\end{array}$ \\
\hline KEK PF-AR Tsukuba, J & $\begin{array}{l}\text { angiography, micro-angiography, monochromatic CT, } \\
\text { DEI, fluorescent X-ray imaging }\end{array}$ \\
\hline NSLS, Brookhaven, US & DEI \\
\hline Siberia-2 Moscow, RUS & DEI \\
\hline ESRF Grenoble, F & angiography, functional lung imaging, DEI, MRT, PAT \\
\hline ELETTRA Trieste, I & $\begin{array}{l}\text { conventional absorption radiology and tomography, PCI, } \\
\text { DEI }\end{array}$ \\
\hline Spring-8 Hyogo, J & $\begin{array}{l}\text { angiography, micro-angiograpy, DEI, PCI, CT, } \mu \text { CT, } \\
\text { MRT }\end{array}$ \\
\hline $\begin{array}{l}\text { Canadian LS Saskatoon, } \\
\text { CA [44] }\end{array}$ & $\begin{array}{l}\text { absorption imaging, DEI, MIR, PCI, CT, MRT, CT ther- } \\
\text { apy }\end{array}$ \\
\hline Australian LS Mel- \\
bourne, AUS [45]
\end{tabular}

\section{SR techniques in biology and medicine}

Applications of synchrotron radiation in the fields of biology and medicine can be divided into four wide categories.

The first category includes scientific investigations aimed on cognition and understanding of life processes in their physiological and pathological aspects, as well as study of biomedical treatment on organisms and developmental work on new diagnostic and therapeutic techniques. SR sources are particularly useful to these types of research activity. Actually a vast majority of synchrotron applications in the fields of biology and medicine belong to this category. An example here can be extensive studies with SR on functioning and pathology of central neural system (CNS) in animals and humans. Some key aspects of the CNS functioning, challenging also in context of cancer, remain unanswered. Many types of brain tumors are malignant with strong tendency to spread. Conventional onco- 
TABLE V

Expansions of acronyms commonly used in SR biomedical radiology.

\begin{tabular}{l|l}
\hline \hline CT & computer tomography \\
$\mu \mathrm{CT}$ & micro computer tomography \\
SRCT & synchrotron radiation computed tomography \\
MRT & microbeam radiotherapy \\
PAT & photon activated therapy \\
KES & K-edge subtraction imaging = dichromography \\
MIR & multiple image radiography \\
CAI & conventional absorption imaging \\
PC, PhC & phase contrast \\
PCI & phase contrast imaging \\
PC-CT & phase contrast computed tomography \\
USAXS & ultra small angle X-ray scattering \\
SAXS & small angle X-ray scattering \\
WAXS & wide angle X-ray scattering \\
TSI & temporal subtraction imaging \\
BM & bending magnet \\
W & wiggler \\
SCW & superconducting wiggler \\
SCMPW & superconducting multipole wiggler \\
U & undulator
\end{tabular}

logic treatment like neurosurgery or radiotherapy carry a high risk due to possible damage of the intact neural tissue surrounding malignant tumor to be eliminated. As a result, serious permanent brain dysfunctions can occur. It is expected to develop with SR new precise diagnostic techniques, as it happened in case of breast cancer [18] as well as methods of efficient CNS therapy.

Second category comprises diagnostic applications of SR aimed on precise recognition of pathology in tissues and cells. Here rank all imaging methods based on absorption contrast and specific to the synchrotron radiation sources, new modalities making use of phase contrast. Some diagnostic techniques exploit photons of lower energies, for example infrared beams for various IR spectroscopic and microscopic methods. Soft X-rays are successfully applied in SR microscopy, offering a resolution of up to $100 \AA$ in imaging of wet biological samples. A pathological process is, as a rule, associated with modifications in biochemistry of cells or tissues, that are manifested in structural changes of these objects. Thus, a sensitive method of probing the molecular and cell irregularities will detect, in principle, the pathological state. To accomplish this, a variety of experimental 
techniques exploiting SR has been developed. A typical example is small angle X-ray scattering (SAXS), capable to provide information on molecular structure of live tissues. It enables to pick up subtle changes in ordering of molecules in extracellular matrix. Another technique, prospective to diagnostics is, mentioned above, IR spectroscopy. In some SR centers, in this number at Canadian Light Source (CLS, Saskatoon), the methods aimed on application of micro-IR spectroscopy coupled with microscopy are extensively developed to identify transformed brain tumor cells. At the same time, feasibility and reliability of the methods are studied, especially in clinical diagnostics (among other places at the Australian Light Source, ALS in cooperation with Monash University).

Third category of biomedical SR applications covers specific methods of therapy, first of all oncotherapy. New, SR versions of two radiotherapy methods, the microbeam radiotherapy (MRT) and the photon-activated therapy (PAT), are here particularly promising. MRT with synchrotron radiation has been shown on animals to destroy efficiently brain cancer cells sparing at the same time surrounding intact neural and connective tissue cells. This diminishes a risk of necrosis and enhancing conservation of functional cerebral integrity. Underway are studies aimed on combining the diagnostic information with therapy in one technique. An example here is a project of application of the mentioned above SR enhanced IR spectroscopy to map places that will be irradiated by MRT. The MRT and PAT will be discussed further in this article.

The last category consists developmental work, aimed on adaptation of SR biomedical techniques of measurement, diagnosis and therapy to the specificity of conventional equipment in hospitals and research centers, to use them as laboratory methods without synchrotron sources.

\section{X-ray imaging with synchrotron radiation 4.1. Absorption contrast imaging with $S R$}

Formation of absorption contrast is dependent on effective atomic numbers related to electron density distribution of materials. Linear absorption coefficients are functions of these magnitudes, as well as of photon energy. Conventional X-ray tubes produce incoherent, uncollimated radiation composed of discrete characteristic lines imposed on bremsstrahlung intensity, that forms a continuous distribution of radiation over photon energy scale. Even with absorption filters that strongly suppress unwanted wavelengths in the emitted beam, the contrast and spatial resolution of an absorption image is lowered by a number of effects related to large focus size, lack of coherence, spread of absorption coefficients over photon energy, the effect of radiation hardening along the beam path in a specimen. The above effects contribute to a relatively low signal/noise ratio due to scattering of photons of inappropriate energies and directions. Application of a synchrotron source improves contrast and resolution of classical radiographic imaging methods thanks to its characteristic properties: an excellent collimation, small angular dimensions of the source, partial coherence and a possibility of wavelength optimization. 
Enhancement of absorption contrast in imaging techniques with SR can be achieved by monochromatization of the X-ray beam. The wavelength can be easily tuned to fit the type of a tissue or a contrast agent, if applicable. Angiography is among earliest diagnostic methods clinically applied with monochromatic SR beams, a.o. at synchrotrons NSLS (Brookhaven), DORIS III (Hamburg) [19], and in KEK (Tsukuba) [20]. In use there are also other, strictly SR techniques, like dichromography (known also as $K$-edge subtraction (KES)), for the first time clinically applied to coronarography at SSRL (Berkeley), diagnosing first patients as early as in 1986. Dichromography utilizes two monochromatic X-ray beams of slightly different photon energies bracketing the absorption edge of a contrast agent in investigated object. An experimental setup of this technique is explained in Fig. 1. Intense white beam (W) from bending magnet or a wiggler is monochromatized and focused by a bent Laue monochromator $(\mathrm{M})$. Two narrow beams, $\mathrm{B}_{1}$ and $\mathrm{B}_{2}$, of various wavelengths are selected on output with a beam stopper $(\mathrm{S})$ and a system of slits (not shown here). The object is placed in the focus and scanned perpendicularly to beams. It can be also rotated, in a dichromographic computed tomography (DCCT) mode. The intensities are recorded line-by-line in a double detector system (D), and collected in a computer system. Final image is formed with maximally enhanced contrast, mapping the distribution of a contrast agent by a logarithmic subtraction of two partial images. In use there is also a version of the technique with monochromatic beams being so wide, that no scanning is necessary. Dichromography with iodine agent maps tiny differences in its concentration, typically below $1 \mathrm{mg} / \mathrm{cm}^{3}$. A concentration of injected intravenously contrast agent can be diminished, as compared to conventional methods, more than hundred times, that drastically lowers a risk of complications.

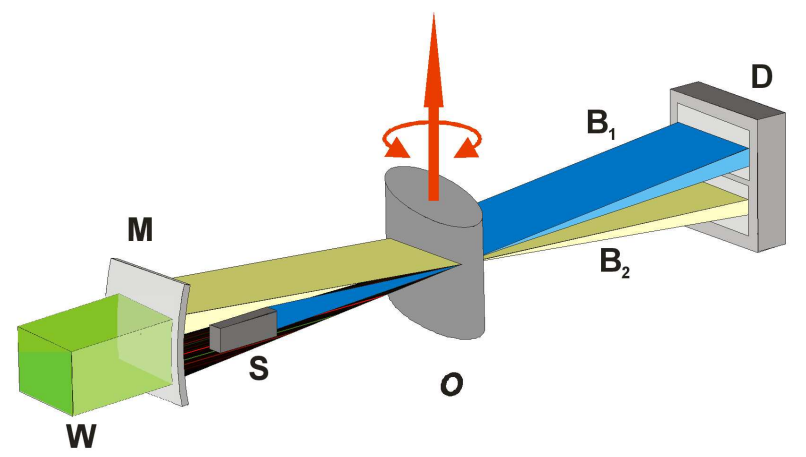

Fig. 1. Sketch of KES scanning imaging technique with SR source. See text for details.

Near 400 patients were examined by the year 2001 at DORIS III (Hamburg) with the NIKOS system based on this technique. Results of this investigation demonstrated a high spatial resolution of the technique, effecting in images revealing changes in blood vessels of diameters as small as $0.6-0.8 \mathrm{~mm}$. SR dichro- 
mography has been confirmed to be minimally invasive diagnostic technique of imaging of the coronary vessels, capable to monitor results of stents and bypasses introduced in coronary arteries. No complications related to diagnostic procedure were registered during the whole series of experiment evidencing a negligible risk of the method [21]. A number of merits of the synchrotron radiation dichromography (SR-DCI) over other competitive techniques, like magnetic resonance imaging (MRI), electron beam computer tomography (EBCT) and multi-slice computer tomography (MSCT) have been evidenced. SR-DCI was found to be of highest spatial resolution, 3-4 times better than that for the other techniques. Assessment of coronary arterial segments conditions was not disturbed by calcification or by presence of metallic stents (like it is in case of MRI). Also problems due to movements of respiratory system disappeared [22]. Similar study has been performed at KEK-PF synchrotron in Tsukuba, with 3D imaging of coronary vessels, at medical line ID-17 in ESRF, Grenoble [23] and at NSLS (Brookhaven).

Apart coronarography, SR-DCI was successfully employed to imaging of lung functioning (bronchography), with inhalated xenon as a contrast agent. This made it possible to monitor bronchioles of diameters below $1 \mathrm{~mm}$. A quantitative comparison of in vivo KES imaging with SR computed tomography (SRCT) and temporal subtraction imaging (TSI) of rabbit lung has been done. The TSI technique relies on the reference image taken before the introduction of the contrast agent. Similar results for concentrations of iodine in blood vessels and xenon in airways were obtained by KES and TSI, but the level of noise and artifacts was higher in the latter. The two methods were combined for the simultaneous determination of the xenon concentration (by KES) and the iodine concentration (by TSI) in lung imaging. This allows simultaneous in vivo determination of ventilation and perfusion [24]. SRCT with monochromatic X-ray beams has been applied for quantitative in vivo brain perfusion measurements. With this technique, high-resolution absolute cerebral blood volume and blood-brain barrier permeability coefficient measurements were obtained on a rat glioma model [25]. The obtained images resulted in the first in vivo high-resolution brain vasculature parameter assessment giving thus interesting perspectives to accurately quantify brain hemodynamic changes in healthy and pathological objects.

\subsection{Phase sensitive $X$-ray imaging}

Phase contrast (PC) is formed as a result of phase shifts introduced in a coherent X-ray beam passing through a specimen. Phase contrast is, in the range of photon energies between 15 and $25 \mathrm{keV}$, up to $10^{3}$ times more sensitive to small differences in structure and composition of a soft tissue as compared to absorption contrast forming a conventional radiography image. Due to this sensitivity, phase effects can be monitored even in cases, where absorption differences are extremely small $[1,26,27]$. In addition, phase contrast image, recorded at lower irradiation dose, can be of higher resolution. 
Several techniques exploiting PC principles are applied in a SR diagnostics, depending on wavelength, properties of object being investigated and radiation characteristics of SR source. Commonly used are: X-ray interferometry (XRI), diffraction enhanced imaging (DEI), and in-line phase-contrast radiography.

In Fig. 2 experimental setups of the techniques are compared. In XRI (Fig. 2A) an X-ray interferometer consisting of three perfect crystals acting as phase-coherent beam splitters and reflectors, generates interference pattern. It reproduces the phase changes introduced by a sample placed in one of the beam paths. On the exit, the image is recorded by a $2 \mathrm{D}$ detector. The XRI technique, of a very high sensitivity, is usually limited to objects not larger than small animals, as it makes use of an X-ray monolithic interferometer.

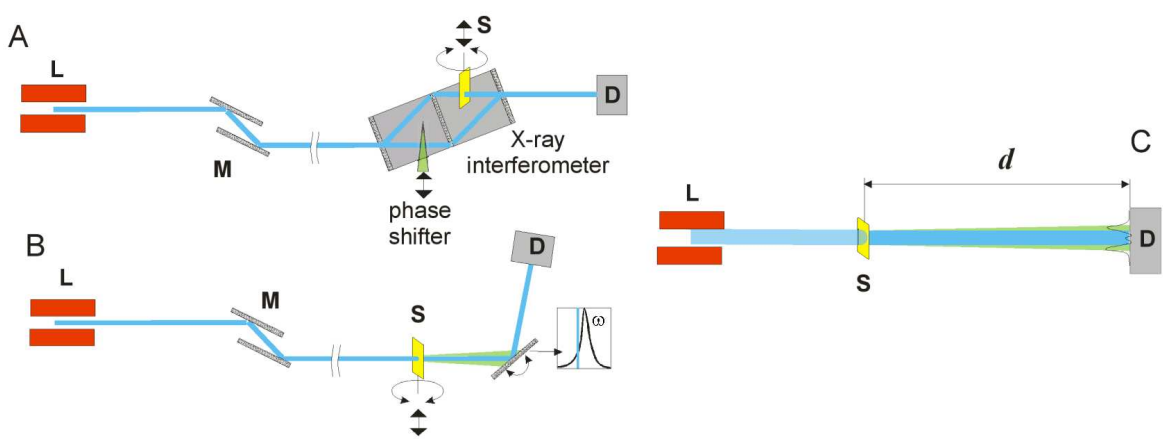

Fig. 2. Experimental setups for phase-sensitive imaging: (A) X-ray interferometry, (B) DEI, (C) in-line phase-contrast imaging. L - SR source, M - double-crystal monochromator, $\mathrm{S}-$ specimen, $\mathrm{D}-2 \mathrm{D}$ detector. For the DEI, an intensity distribution at the position of the analyzer crystal is shown in the inset. See text for details.

In diffraction-enhanced imaging (DEI, Fig. 2B), formation of image is affected by absorption, by refraction as well as by extinction (by a controlled cutting the rays scattered at small angles) of monochromatic X-ray beam passing through the object. This distinguishes the DEI technique from conventional radiographic methods, where image is formed exclusively by absorption. Between the investigated object $(\mathrm{S})$ and the detector $(\mathrm{D})$ a monocrystalline analyzer is set, that acts as an angular filter. The analyzer selects a narrow band of radiation at a fixed angular position with respect to the Bragg maximum, and blocks X-rays exiting from the specimen in other directions (Fig. 2B, inset). Due to this, the image is almost entirely free of components coming from scattered radiation. This way, DEI gains contrast of soft tissue image for objects that are not capable to create sufficiently high absorption contrast. Moreover, by tuning precisely angular position of the analyzer crystal, it is possible to extract information included in radiation intensity distribution scattered at small angles (usually on the order of a microradian and below). The DEI technique makes it possible to quantitatively separate pure absorption effect from pure refraction effect [28]. 
In-line phase-contrast imaging setup (Fig. 2C) relies on the detector placed sufficiently far behind the sample. As the X-ray beam passes through the sample, wave-front distortions are generated producing interference fringes that can be recorded by the detector. At an appropriate object-image distance, these fringes yield edge enhancements in the image.

SR phase contrast methods were successfully employed in imaging of breast tissue (mammography) at medical line SYRMEP at ELETTRA (Trieste), effecting in images of exceptional resolution and contrast as compared with conventional absorption techniques $[29,30]$. In addition, images are formed at significantly lower, even of 30-40\%, irradiation doses. Results collected during few years lasting preclinical studies at SYRMEP turned out so much encouraging, that, since April 2007, a clinical phase of experiment started with participation of human patients (project SYRMA), aimed on refinement of SR mammography. Initially, breast images will be recorded with a conventional screen-film system, that will be later replaced by a 2D detector with a digital matrix linked to an image processing computer [31].

\section{Radiotherapy with synchrotron radiation}

High irradiation doses, necessary to destroy a pathologically transformed tissue, are almost equally damaging to healthy cells surrounding the tumor. That is especially essential in treatment of tumors localized in central nervous system. As a consequence of radiotherapy, a risk of neurological disorders, impairments increases. In extreme, the treatment can lead even to death of patient. For a conventional radiotherapy (with X-ray or nuclear sources) a number of techniques have been developed to minimize the negative side effects of radiological treatment. Unfortunately, still in too many cases the procedures are inefficient.

Introduction in the tumor of a compound containing a heavy atom marker is commonly used to enhance cure effect of radiotherapy and to limit at the same time side effects. Some compounds containing marker atoms, like iodine or gadolinium, bind specifically to cancerous transformed cells [32]. Enhancement of therapeutic efficiency of radiation dose occurs due to absorption of radiation by heavy marker atoms, concentrated within the tumor volume. This leads to strong emission of excited short-range photoelectrons, that directly damage only surrounding cancer cells, without affecting more distant healthy tissues [33]. Together with excellent collimation and high intensity, tunability makes the SR especially suitable to this type of therapy, known as PAT. With the tunability, it is easy to adjust photon energy to absorption edge of the marker atoms introduced in tumor. Due to optimal excitation of photoelectric effect in marker atoms localized possibly close to DNA of tumor cells, the electrons excited by radiation effectively destroy both DNA strands. Ability of cells to repair this type of damage is much lower, as compared to damage of a single strand only.

To the commonly applied PAT markers belongs cisplatin(um) (cisdiamminedichloridoplatinum(II), CDDP), a platinum-based chemotherapeutical 
compound that easily penetrates cell nucleus and binds to cellular DNA. PAT efficiency has been demonstrated even with marker substances, like that containing iodine, which do not bind specifically within nucleus. Studies on rats with glioma, performed in various variants of associated radiotherapy, marker infusion, and in function of X-ray dose have shown that the best therapeutic results were achieved, when cisplatin was introduced in tumor volume directly before irradiation. In this case survival rate was the highest amongst all other observed during preclinical test of various therapies of brain glioma, involving also classical treatment methods [34-36].

Promising results were obtained with new techniques of radiotherapy exploiting strong synchrotron beams in the form of sliced parallel microstrips, known as MRT. The MRT technique relies on the dose-volume effect. Threshold doses for tissue damage increase as the irradiated volumes are made smaller. As high intensity synchrotron X-ray beams with negligible divergence became available, it was shown that the effect can be enhanced by irradiation of tissue volume units in the microscopic range [37]. Healthy tissues, including the neural tissue, have been shown to be very well endured [tolerable] to irradiation with the system of microbeams, and survive the irradiation in a relatively good condition even at very high exposition doses, up to few hundreds Gy. For comparison, typical short-time lethal dose in radiotherapy does not exceed a few Gy. Contrary to this, malignant cells in tumors were selectively destroyed at much lower doses. It was experimentally confirmed with animals that the MRT technique is especially efficient in treatment of tumors located in CNS, and its application is loaded [connected] with a relatively low risk of complications.

Though basic mechanisms of dose-volume effect are not yet well understood, they obviously have to involve processes of regeneration of damaged microvasculature and glial cell system in volumes where microbeam radiation affects intact (non-cancerous) tissue. Rapid repair of microscopic lesions seem to be facilitated by adjacent endothelial, oligodendroglial and other support cells from regions free of radiation between the microbeam stripes. MRT technique was applied with synchrotron radiation firstly in the early years 1990, using radiation produced in a strong superconducting wiggler of X17B beamline at NSLS synchrotron (Brookhaven). Soon after, in 1996 it was employed in ESRF (Grenoble) and in SPring-8 (Hyogo). Recent investigations indicate that the MRT effect conserving healthy tissue is still significant even at strip sizes as large as $0.68 \mathrm{~mm}$. A modification of the MRT technique is in use, where two microbeam systems are entering the specimen from two different directions crossing alternately in the volume of tumor, forming in this region a continuous irradiated stack. As a result, a much higher dose of radiation is delivered to the tumor, while surrounding cells are irradiated only with segmented system of microbeams. Results on rats with gliosarcoma treated with MRT have confirmed full ablation of brain tumors with only a little normal brain damage [38]. It has been found that the brain-sparing 
effect disappears when the valley dose (between beam microstrips) approaches the tissue tolerance to broad beams. Doses up to $625 \mathrm{~Gy}$ in adult rat brain, delivered with microplanar beams of the width $20-42 \mu \mathrm{m}$ had no effect on healthy neural tissue. The post-irradiation observation period was kept for about 1 year. Present state of the art of the MRT technique with synchrotron radiation is about to pass soon from pre-clinical phase to its application in cancer therapy for humans [39].

Promising results were obtained with technique combining PAT and MRT with cisplatin as a marker. A complete damage of brain tumors in laboratory animals (a.o. rats, rabbits and pigs) was achieved with this treatment without any traces of neurological side effects. These methods of SR therapy are considered, in case of some types of CNS tumors, like glioma, to be potentially the most effective form among other medical treatments. This contributes to interest in development of SR stations to brain radiotherapy and diagnostics. The number of already existing SR centers at NSLS (USA), SPring-8 (Japan), or ESRF (France), will soon grow with newly designed for national synchrotron radiation sources constructed in Spain, Australia, Canada, Jordan and, hopefully, in Poland and in Czech Republic. Underway are, especially in USA and Japan, projects of compact sources of SR, of relatively small sizes, simpler and slightly less brilliant, that could be installed in larger hospitals and laboratories to radiodiagnosis and radiotherapy.

Successes reached in preclinical phase of new therapeutic methods, like MRT or PAT effected in growth of interest in construction of possibly strongest SR sources of radiation operating at photon energies of $100 \mathrm{keV}$ and above. This type of sources is of primary importance to synchrotron clinical applications in diagnosis and radiotherapy. For instance, new SR sources designed for NSLS and NSLS II storage rings will deliver beams of photon energies above $150 \mathrm{keV}$ (in order to increase penetration length) and of spectral brightness that will make possible to reach absorbed exposition rates higher than $2000 \mathrm{~Gy} / \mathrm{s}$. Owing to this, exposition rates of the order of few to 100 Gy of monochromatized beam, will be delivered to a patient in a fraction of a second, faster than a heartbeat. For comparison, SR source at X17B1 beamline of NSLS delivers beam capable to give exposition rate of $40 \mathrm{~Gy} / \mathrm{s}$ at critical energy of $12 \mathrm{keV}$. Intense SR sources operating with higher critical energy open up new possibilities in application of phase contrast techniques, to imaging the objects as large as human head in a reasonably short time.

Preclinical experiments are, for obvious reasons, performed with animals and not with human patients. It is therefore especially important to keep the highest possible standards not only scientific but ethical as well. On SR stations, it is achieved by carefully tested procedures, clear regulations and organization of work, as well as by proper space arrangement, room construction, that allows to carry out investigations in optimal conditions both to live objects being investigated and to investigators. 


\section{Adapting synchrotron techniques to conventional sources}

Usefulness of clinical methods strongly benefits with their accessibility and reliability in everyday medical practice. As it is not possible to transport all qualified patients to synchrotron centers, or to adapt large-sized synchrotron facilities in hospital environment, it is desirable that a radiodiagnostic or therapeutic method is applicable with a standard, commercial X-ray generators. Therefore, whenever possible, transfer of SR specific techniques to work with conventional sources is of big importance. Though a vast majority of SR unique properties is not achievable with standard X-ray tubes, some of the techniques originally developed for SR, can be adapted to operate with slightly modified conventional laboratory sources or with more intense types of compact sources, being extensively developed (for application of X-ray sources utilizing the inverse-Compton scattering in monochromatic imaging see, e.g. [40]).

Based on SR technique, a system for dichromography was developed adapted to a compact rotating anode X-ray source with a bent Laue monochromator. Characteristic lines of the cerium and barium targets from Laue diffraction were used to obtain images above and below $K$-edge of a iodine contrast agent. Digital subtraction of the images produced a resulting iodine distribution image [41].

A recent example is phase contrast computed tomography (PC-CT). After adapting to conventional X-ray generator with grating interferometers, good quality phase-contrast radiographic images of static biological objects have been obtained [42]. With this technique, a high resolution 3D reconstruction of a big hornet has been achieved. Revealed details of internal structures of the insect were surprisingly clear [43].

\section{Final remarks}

SR applications in biology and medicine cover today a broad range of tasks, from scientific research on anatomy, physiology and pathology, up to clinical trials of new SR specific radiotherapy techniques. It strongly enhances the exploration of the dynamics of pathology at various scales, from body as a whole, up to molecular level. Thus SR gives a significant contribution in pursuit of fundamental improvements to health. In recent years the gravity point of biomedical SR applications shifts pronouncedly from studies of purely cognitive aims, toward preclinical and clinical treatment and diagnosis on live organisms of animals and humans.

Synchrotron radiation offers a number of new, specific methods together with improved older techniques of investigation, contributing to deeper insight in mechanisms of vital biological processes in plants, animals and humans. It forms an excellent tool in search for efficient and safer ways of diagnosis and therapy. Especially promising are here results in CNS tumors treatment. In case of some cancer diseases it has been evidenced that SR radiotherapy provides presently the highest chances of recovery amongst all other.

The infrastructure and expertise of professionals concentrated around SR centers serve to integration of basic scientific research with applied biology and 
medicine, breaking through traditional barriers, and combining next generation research technology with a range of existing capabilities.

\section{Acknowledgments}

This work was partially supported by the grant of Ministry of Science and Higher Education of Poland, SPB no. DESY/68/2007.

\section{References}

[1] R. Meuli, Y. Hwu, J.H. Je, G. Margaritondo, Eur. Radiol. 14, 1550 (2004).

[2] G. Margaritondo, Y. Hwu, J.H. Je, Rivista Nuovo Cimento 27, 1 (2004).

[3] T.L.-M. Sorensen, K.E. McAuley, R. Flaig, E.M.H. Duke, Trends Biotechnol. 24, 500 (2006).

[4] Table has been based on data reported in: J.H. Hubbell, S.M. Seltzer, Tables of X-Ray Mass Attenuation Coefficients and Mass Energy-Absorption Coefficients from $1 \mathrm{keV}$ to $20 \mathrm{MeV}$ for Elements $Z=$ 1 to 92 and 48 Additional Substances of Dosimetric Interest, NIST, http://physics.nist.gov/PhysRefData/XrayMassCoef/cover.html.

[5] The term spectral brightness is used throughout this paper, instead of often used brightness, following discussion in: D.M. Mills, J.R. Helliwell, A. Kvick, T. Ohta, I.A. Robinson, A. Authier, J. Synchrotron Rad. 12, 385 (2005).

[6] TESLA Technical Design Report, Part V, The X-ray Free Electron Laser, Eds. G. Materlik, Th. Tschentscher, DESY, Hamburg 2001.

[7] H. Elleaume, A.-M. Charvet, J.-F. Le Bas, Acta Radiol. Suppl. 412, 29 (1997).

[8] A.L. Robinson, in: X-ray Data Booklet. Center for X-ray Optics and Advanced Light Source, 2001, Sect. 1, p. 17 (available on-line at http://xdb.lbl.gov/).

[9] K.-J. Kim, in Ref. [8], Sect. 1, p. 1.

[10] N. Patel, Nature 415, 110 (2002).

[11] TESLA Technical Design Report, Part II, Eds. R. Brinkmann, K. Floettmann, J. Rossbach, P. Schmueser, N. Walker, H. Weise, Deutsches Elektronen Synchrotron DESY, Hamburg 2001.

[12] R. Neutze, R. Wouts, D. van der Spoel, E. Weckert, J. Hajdu, Nature 406, 752 (2000).

[13] R. Neutze, G. Huldt, J. Hajdu, D. van der Spoel, Radiat. Phys. Chem. 71, 905-916 (2004).

[14] H.N. Chapman, A. Barty, M.J. Bogan, S. Boutet, M. Frank, S.P. Hau-Riege, S. Marchesini, B.W. Woods, S. Bajt, W.H. Benner, R.A. London, E. Plönjes, M. Kuhlmann, R. Treusch, S. Düsterer, T. Tschentscher, J.R. Schneider, E. Spiller, T. Möller, C. Bostedt, M. Hoener, D.A. Shapiro, K.O. Hodgson, D. van der Spoel, F. Burmeister, M. Bergh, C. Caleman, G. Huldt, M.M. Seibert, F.R.N.C. Maia, R.W. Lee, A. Szöke, N. Timneanu, J. Hajdu, Nature Phys. 2, 839 (2006).

[15] S.P. Hau-Riege, H.N. Chapman, J. Krzywinski, R. Sobierajski, S. Bajt, R.A. London, M. Bergh, C. Caleman, R. Nietubyc, L. Juha, J. Kuba, E. Spiller, S. Baker, R. Bionta, K. Sokolowski-Tinten, N. Stojanovic, B. Kjornrattanawanich, E. Gullikson, E. Plönjes, S. Toleikis, T. Tschentscher, Phys. Rev. Lett. 98, 145502 (2007). 
[16] J. Chalupský, L. Juha, J. Kuba, J. Cihelka, V. Hájková, S. Koptyaev, J. Krása, A. Velyhan, M. Bergh, C. Caleman, J. Hajdu, R.M. Bionta, H. Chapman, S.P. HauRiege, R. A. London, M. Jurek, J. Krzywinski, R. Nietubyc, J.B. Pelka, R. Sobierajski, J. Meyer-ter-Vehn, A. Tronnier, K. Sokolowski-Tinten, N. Stojanovic, K. Tiedtke, S. Toleikis, T. Tschentscher, H. Wabnitz, U. Zastrau, Opt. Express 15, 6036 (2007).

[17] J.L. Laclare, Nucl. Instrum. Methods Phys. Res. A 467-468, 1 (2001).

[18] G. Falzon, S. Pearson, R. Murison, C.J. Hall, K.K.W. Siu, A. Evans, K.D. Rogers, R.A. Lewis, Phys. Med. Biol. 51, 2465 (2006).

[19] W.-R. Dix, Prog. Biophys. Molec. Biol. 63, 159 (1995).

[20] Y. Sugishita, S. Otsuka, Y. Itai, T. Kakeda, M. Ando, K. Hyodo, Abstracts of 10th Meeting of the Jap. Soc. for Synchrotron Radiation Research, 1997, p. 1.

[21] T. Dill, W.-R. Dix, C.W. Hamm, M. Jung, W. Kupper, M. Lohmann, B. Reime, R. Ventura, Eur. J. Phys. 19, 499 (1998).

[22] W.-R. Dix, W. Kupper, T. Dill, C.W. Hamm, H. Job, M. Lohmann, B. Reime, R. Ventura, J. Synchrotron Rad. 10, 219 (2003).

[23] H. Elleaume, S. Fiedler, B. Bertrand, T. Brochard, F. Estève, J.F. Le Bas, G. Le Duc, C. Nemoz, M. Renier, P. Suortti, W. Thomlinson, Phys. Med. Biol. 45, L39 (2000).

[24] H. Suhonen, L. Porra, S. Bayat, A.R. Sovijärvi, P. Suortti, Phys. Med. Biol. 53, 775 (2008).

[25] J.-F. Adam, C. Nemoz, A. Bravin, S. Fiedler, S. Bayat, S. Monfraix, G. Berruyer, A.M. Charvet, J.-F. Le Bas, H. Elleaume, F. Estève, Cereb Blood Flow Metab. 25, 145 (2005).

[26] A. Bravin, J. Phys. D, Appl. Phys. 36 (10A), A24 (2003).

[27] T. Takeda, Nucl. Instrum. Methods Phys. Res. A 548, 38 (2005).

[28] F. Arfelli, AIP Conf. Proc. 630, 1 (2002).

[29] A. Abrami, F. Arfelli, R.C. Barroso, A. Bergamaschi, F. Bille, P. Bregant, F. Brizzi, K. Casarin, E. Castelli, V. Chenda, L. Dalla Palma, D. Dreossi, C. Fava, R. Longo, L. Mancini, R.-H. Menk, F. Montanari, A. Olivo, S. Pani, A. Pillon, E. Quai, S. Ren Kaiser, L. Rigon, T. Rokvic, M. Tonutti, G. Tromba, A. Vascotto, C. Venanzi, F. Zanconati, A. Zanetti, F. Zanini, Nucl. Instrum. Methods Phys. Res. A 548, 221 (2005).

[30] C. Venanzi, A. Bergamaschi, F. Bruni, D. Dreossi, R. Longo, A. Olivo, S. Pani, E. Castelli, Nucl. Instrum. Methods Phys. Res. A 548, 264 (2005).

[31] E. Castelli, F. Arfelli, D. Dreossi, R. Longo, T. Rokvic, M.A. Cova, E. Quaia, M. Tonutti, F. Zanconati, A. Abrami, V. Chenda, R.H. Menk, E. Quai, G. Tromba, P. Bregant, F. de Guarrini, Nucl. Instrum. Methods Phys. Res. A 572, 237 (2007).

[32] A. Norman, M. Ingram, R.G. Skillen, D.B. Freshwater, K.S. Iwamoto, T. Solberg, Radiat. Oncology Investig. 5, 8 (1997).

[33] H.T. Rose, A. Norman, M. Ingram, C. Aoki, T.D. Solberg, A. Mesa, Int. J. Radiation Oncology Biol. Phys. 45, 1127 (1999). 
[34] W. Thomlinson, P. Suortti, D. Chapman, Nucl. Instrum. Methods Phys. Res. A 543, 288 (2005).

[35] M.C. Biston, A. Joubert, J.F. Adam, H. Elleaume, S. Bohic, A.M. Charvet, F. Esteve, N. Foray, J. Balosso, Cancer Res. 64, 2317 (2004).

[36] H.M. Smilowitz, H. Blattmann, E. Bruer-Krisch, A. Bravin, M. Di Michiel, J.O. Gebbers, A.L. Hanson, I. Lyubimova, D.N. Slatkin, J. Stepanek, J.A. Laissue, J. NeuroOncology 78, 135 (2006).

[37] D.N. Slatkin, P. Spanne, F.A. Dilmanian, J.O. Gebbers, J.A. Laissue, Proc. Natl. Acad. Sci. U S A 92, 8783 (1995).

[38] J.A. Laissue, G. Geiser, P.O. Spanne, F.A. Dilmanian, J.-O. Gebbers, M. Geiser 4, X.-Y. Wu, M.S. Makar, P.L. Micca, M.M. Nawrocky, D.D. Joel, D.N. Slatkin, Int. J. Cancer 78, 654 (1998).

[39] A. Laissue, H. Blattmann, M. Di Michiel, D.N. Slatkin, N. Lyubimova, R. Guzman, W. Zimmermann, S. Birrer, T. Bley, P. Kircher, R. Stettler, R. Fatzer, A. Jaggy, H.M. Smilowitz, E. Brauer, A. Bravin, G. Le Duc, C. Nemoz, M. Renier, W. Thomlinson, J. Stepanek, H.-P. Wagner, Proc. SPIE 4508, 65 (2001).

[40] F.E. Carroll, Am. J. Roentgenol. 179, 583 (2002).

[41] Z. Zhong, D. Chapman, R. Menk, J. Richardson, S. Theophanis, W. Thomlinson, Phys. Med. Biol. 42, 1751 (1997).

[42] F. Pfeiffer, T. Weitkamp, O. Bunk, C. David, Nature Phys. 2, 258 (2006).

[43] F. Pfeiffer, O. Bunk, C. Kottler, C. David, Phys. Rev. Lett. 98, 108105 (2007).

[44] Canadian Light Source Activity Report 2001-2004, Ed. M. Dalzell, CLS Document No. 0.18.1.2, Canadian Light Source Inc. 2005 (http://www.lightsource.ca/).

[45] J.W. Boldeman, D. Einfeld, Nucl. Instrum. Methods Phys. Res. A 521, 306 (2004).

[46] R.A. Lewis, Nucl. Instrum. Methods Phys. Res. A 548, 23 (2005).

[47] A. Bravin, R. Noguera, M. Sabés, J. Sobrequés, ALBA Biomedical Beamline (ABME), A Proposal for the ALBA S.A.C., Barcelona 2004.

[48] PETRA III: A Low Emittance Synchrotron Radiation Source. Technical Design Report, Executive Summary, Eds. K. Balewski, W. Brefeld, W. Decking, H. Franz, R. Röhlsberger, E. Weckert, DESY, Hamburg 2004.

[49] NSLS-II Conceptual Design Report, Brookhaven National Laboratory, 2006.

[50] Scientific Evaluation of the MAX IV Proposal, Vetenskapsrøadets Rapportserie 20:2006, Stockholm 2006. This report can be obtained at www.vr.se/publikationer.

[51] M. Eriksson, B. Anderberg, I. Blomqvist, M. Brandin, M. Berglund, T. Hansen, D. Kumbaro, L.-J. Lindgren, L. Malmgren, H. Tarawneh, S. Thorin, M. Sjöström, H. Svensson, E. Wallén, S. Werin, in: Proc. EPAC 2006, Edinburgh, Scotland 2006, p. 3418; available on-line at: http://accelconf.webcern.ch/AccelConf/e06/PAPERS/THPLS059.PDF. 